\title{
Status of selected mammal species in North Myanmar
}

\author{
Alan Rabinowitz and Saw Tun Khaing
}

During 1996 and 1997, data on the status of selected mammal species were collected from a remote region of North Myanmar. Of the 21 species discussed in this paper, the black muntjac, stone marten and blue sheep are new records for the country. One species, the leaf muntjac, has never been described. At least three species that once inhabited the region - elephant, gaur and Sumatran rhinoceros - are no longer present, and the tiger has been nearly extirpated. Himalayan species that are declining elsewhere, such as takin, red goral and red panda, are still relatively abundant despite hunting pressures. Musk deer are in serious decline. The wolf, while not positively confirmed, may be an occasional inhabitant of North Myanmar.

\section{Introduction}

The area called North Myanmar, between $24-28^{\circ} \mathrm{N}$ and $97-99^{\circ} \mathrm{E}$, is a narrow strip along the western escarpment of Yunnan Province in China, once part of a continuous land formation comprising the Tibetan Plateau to the north and the China Plateau to the east (Kingdon-Ward, 1944). This mountainous region contains floral communities of Miocene origin, which have been isolated since the last glaciation (Kingdon-Ward, 1936, 1944). At the most northern extremities of Myanmar is a sparsely populated, little-explored region that is generally referred to as the 'icy mountains', containing some lesser-known Himalayan peaks, including Mt Hkhakabo-Razi, an estimated $5889 \mathrm{~m}$ high (Figure 1).

Some of the first expeditions into northern Myanmar, north of $27^{\circ} 30^{\prime}$, were carried out in the early 1900 s by botanists Frank KingdonWard and Reginald Farrer, who recorded cursory sightings of wildlife. In 1931, while trying to find the source of the Irrawaddy River (Kingdon-Ward, 1932), Lord Cranbrook collected several hundred bird and mammal specimens (Dollman, 1932; Kinnear, 1934). Otherwise, few zoological data have been collected from this region.

In 1996 the Ministry of Forestry in Myanmar declared the area north of the Nam Tamai River to the Chinese border as Hkakabo-Razi Protected Area (Figure 1), but no government staff had recently visited the region. During March 1996 the authors travelled to the town of Putao and surrounding villages west of the Mali Hka River (Figure 1). The following year, between 23 February and 29 April 1997, a biological expedition was organized with the Forest Department into the Hkakabo-Razi Protected Area, and travelled as far north as Rasang Camp ( $28^{\circ} 21^{\prime} \mathrm{N}, 97^{\circ} 30^{\prime} \mathrm{E}$; Figure 1).

Data on mammal presence and relative abundance were obtained by using photographs and drawings to interview local hunters, and by examining hunters' kills in villages and markets. As a result of a thriving cross-border trade in wildlife parts with China, skins, antlers and horns of larger mammal species present in the area were readily available in villages visited during the expedition. Firearms were virtually non-existent among the local people, but hunting with crossbows, dogs and snares was omnipresent. The accounts that follow, listed in taxonomic order, include new species records for Myanmar and an undescribed deer species. Information is also presented on the status of other mammal species considered to be of conservation interest. 


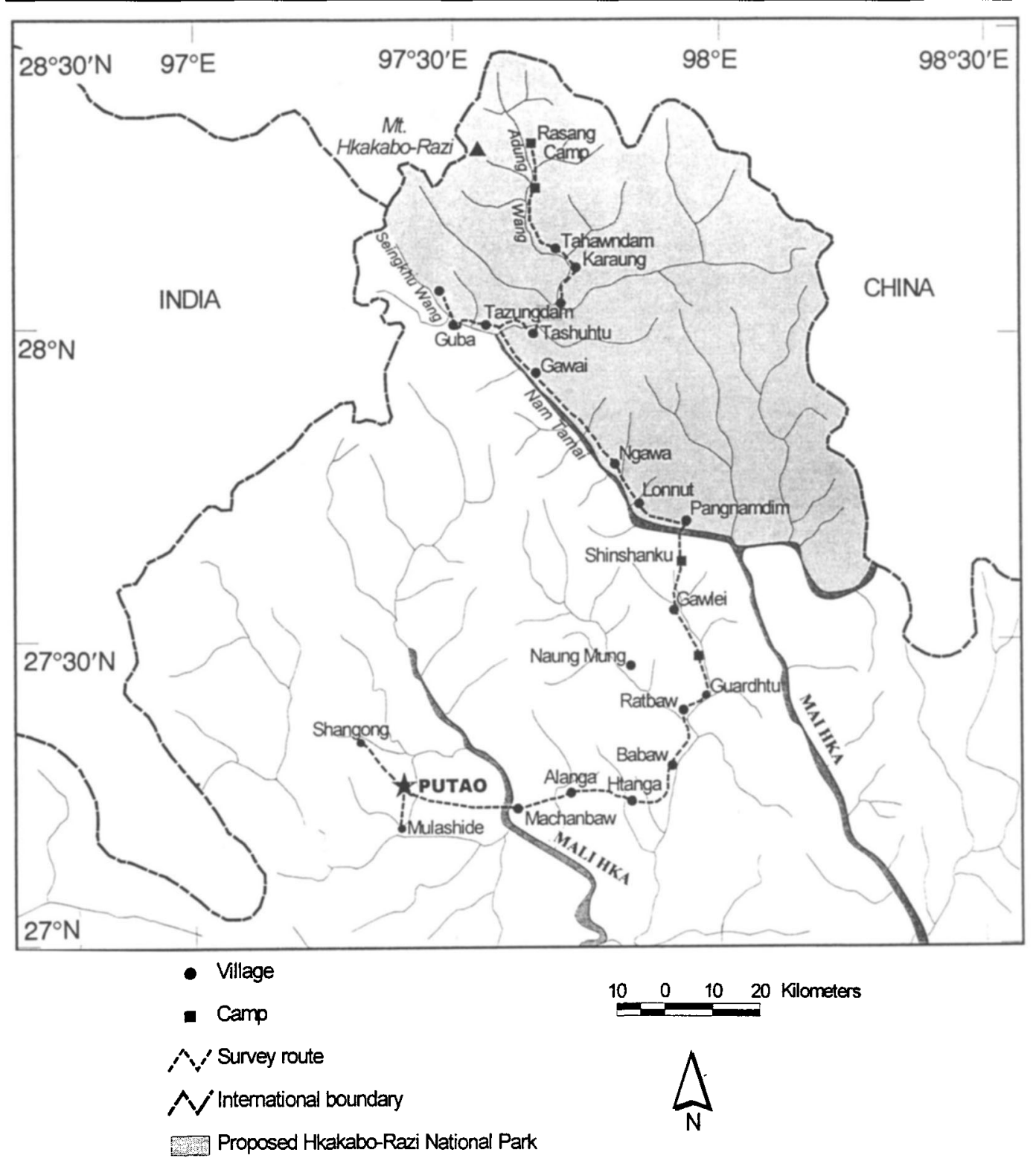

Figure 1. North Myanmar showing the Hkakabo-Razi Protected Area (shaded), survey route and villages visited during the 1996 and 1997 expeditions.

\section{Species accounts}

\section{Family Cervidae}

Barking, or muntjac, deer Muntiacus spp.: During surveys in 1996 and 1997, west of the Mali Hka River, and along the survey route between the Mali Hka and Mai Hka Rivers (Figure 1), hunters consistently described at least three kinds of muntjac, which differed in size and appearance. The smallest, with a reddish coat and found primarily on the mountain tops, was called the 'leaf deer' by local hunters and overlapped in its distribution with a

(C) $1998 \mathrm{FFI}$, Oryx, 32 (3), 201-208 


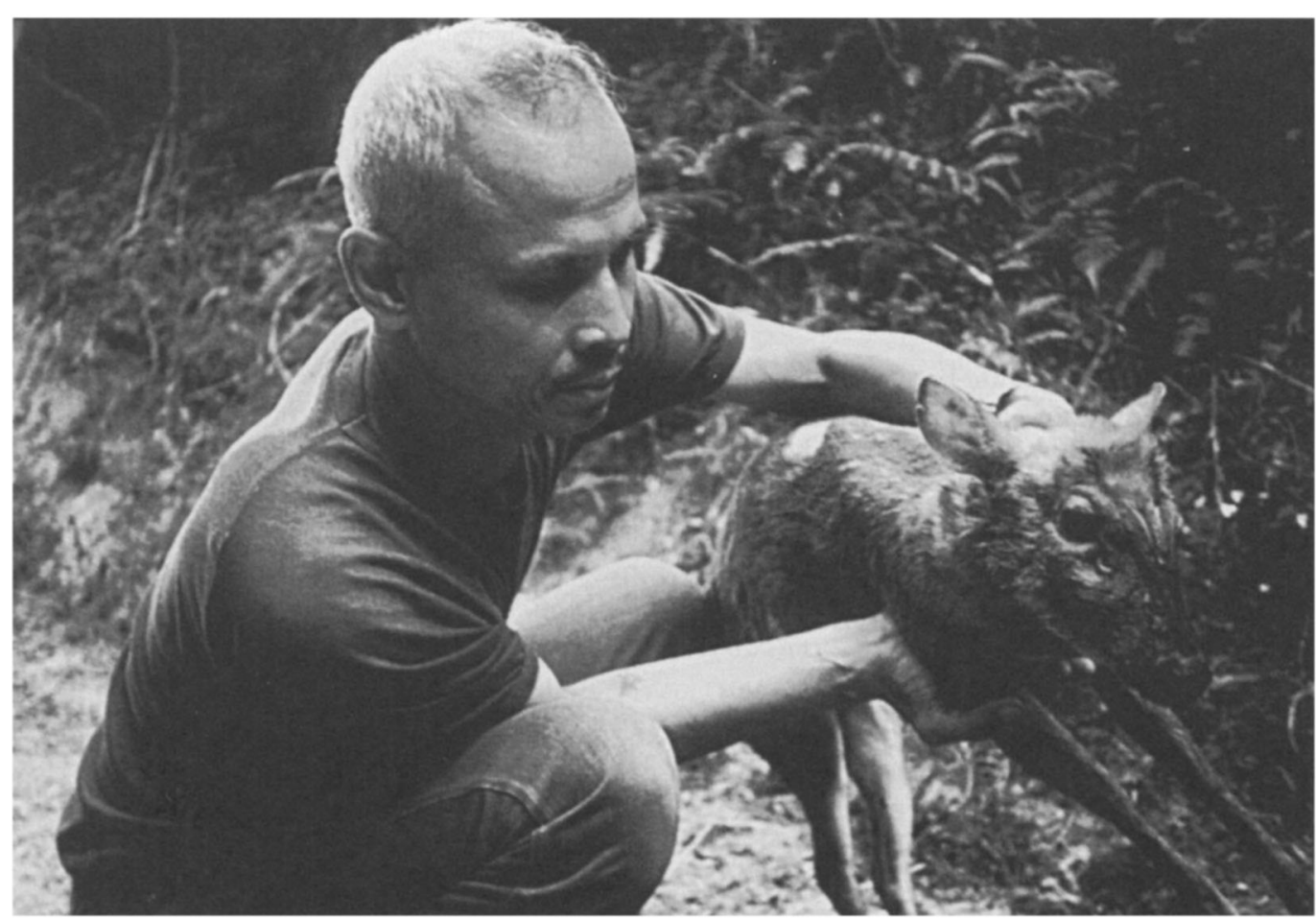

Right. A local hunter emerging from the forest with a freshly snared deer that was later identified as a new species, the leaf muntjac (Alan Rabinowitz). Above. Expedition team member with the adult female leaf muntjac killed by the hunter (Alan Rabinowitz).

medium-sized red barking deer, which was often seen in lowlands and edge habitat. There were also reports of a 'black barking deer' from the far north, beyond the Nam Tamai River. Eventual examination of specimens revealed that two of the deer are new species for Myanmar. The intermediate-sized red deer, which was locally abundant, was the Indian muntjac Muntiacus muntjak. Information on the two new species for Myanmar is given below.

Leaf muntjac Muntiacus sp.: Initial examination of diagnostic DNA character data, along with morphological characteristics of 10 skulls and one freshly killed specimen collected between the villages of Alanga and Shinshanku (Figure 1), unambiguously distinguish this deer from all other known species of muntjac. With short,

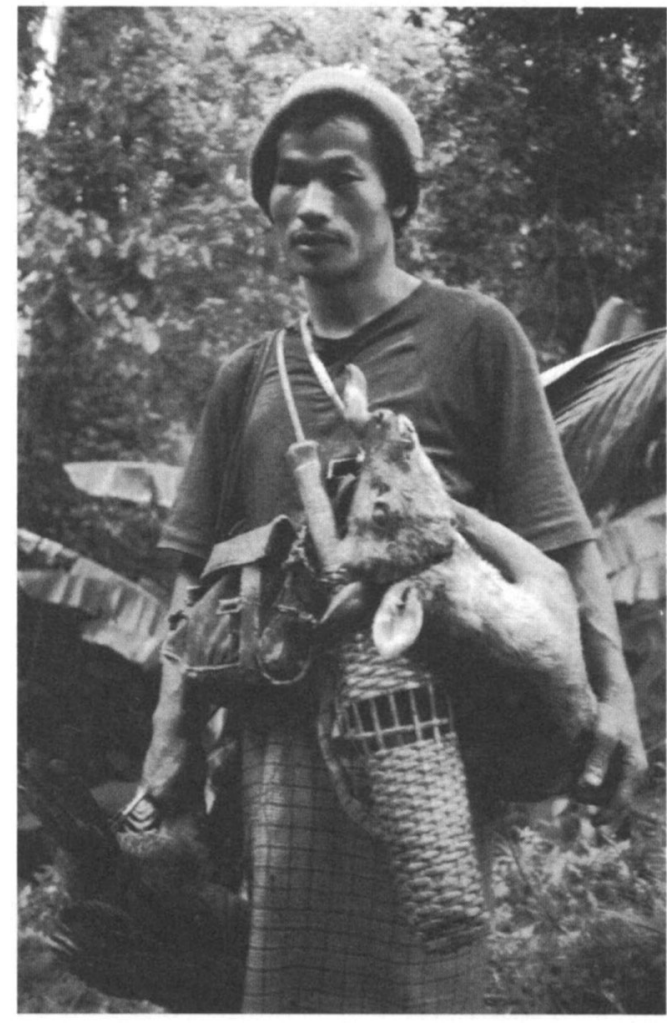


unbranched antlers and a small body that, according to hunters, can be wrapped in a single leaf of a local tree, Phrynium cadellianum (Family Zingiberaceae), this is one of the smallest muntjacs currently known. A more detailed description of the genetics and morphology of this new taxon will be presented in upcoming papers by Amato et al. and Rabinowitz et al.

Throughout its currently known range, comprising the mountainous regions north-east of Putao and south of the Nam Tamai branch of the Mai Hka River (Figure 1), the leaf deer is reported to be relatively common. However, persistent hunting with snares has reduced its numbers over the last decade. One hunter reported taking only three a month, compared with at least twice that number in the past. Although the meat is consumed and the skins are sold to both local and Chinese merchants, the leaf deer is not considered a particularly valuable species because of its small size and almost insignificant antlers.

Black muntjac Muntiacus crinifrons: Since its discovery, the black muntjac has been considered endemic to China, currently restricted to high-altitude forested areas $(800-1000 \mathrm{~m})$ in four provinces of the south-eastern part of the country (Lu and Sheng, 1984). Until 1975, when it was known from only a few museum specimens, this species was considered close to extinction (Cowan and Holloway, 1973). The total population of black muntjac has been estimated at fewer than 10,000 individuals (Ohtaishi and Gao, 1990). Recent declines in numbers are attributed to hunting for the animal's meat and skin (Lu and Sheng, 1984; Wang and $\mathrm{Hu}, 1985$ ).

The recent discovery of this species in Myanmar (Rabinowitz et al., 1998), indicates a current distribution within the newly declared Hkakabo-Razi Protected Area (Figure 1), although there are indications that the species may also occur south of the Nam Tamai in areas not yet surveyed. The characteristic dark coat colour of this deer appeared more pronounced in specimens observed in the more northern villages, with the limit of this species's distribution in Myanmar reported to be approximately $11 \mathrm{~km}$ north of the last village of Tahawndam. Although this deer was one of the most heavily hunted larger animals in the region, it was also considered to be one of the most common. Although no detailed surveys have yet been carried out, Myanmar's population of black barking deer should add significantly to estimates of this species's numbers in the wild.

\section{Family Moschidae}

Musk deer Moschus spp.: There have been several attempts to review the taxonomy of this monogeneric family, which was divided into three species by Gao (1985), and recently into five or six species by Groves et al. (1995). Although the musk deer in Myanmar was listed as Moschus moschiferus by Tun Yin (1967), Groves et al. (1995) listed the species from Myanmar as $M$. fuscus. Recent survey data from the Galigongshan region along the Myanmar border (Ma et al., 1994), and distribution maps by Ohtaishi and Gao (1990), indicate the possibility of two additional species in Myanmar: $M$. sifanicus and $M$. berezovskii. Further investigation is needed to clarify this situation.

Owing primarily to hunting, populations of musk deer in China are declining rapidly (Ohtaishi and Gao, 1990). This is also true in Myanmar, where the musk deer's glands are the most sought-after wildlife parts for trade. Snare lines, sometimes extending several kilometres, are set for these animals in traditional hunting areas. The skins, while not considered valuable for trade, are used for cold-weather hats. Although hunters in the village of Tazungdam still claimed an annual harvest of 15-20 musk deer, other villagers reported much lower numbers of kills. Most hunters considered musk deer to be uncommon to rare, with numbers declining rapidly.

\section{Family Bovidae}

Blue sheep Pseudois nayaur: In 1996 five sets of blue-sheep horns were examined in Putao, having reportedly come from the icy mountains' of the north. Never before documented 
from Myanmar, these animals live above the timberline, in open rocky terrain from 3500 to $5500 \mathrm{~m}$, except in the eastern part of their range in China, where they descend to $2600 \mathrm{~m}$ and lower (Schaller, 1977).

This animal was unknown to all but the most northern hunters, who reported that it occured between Seinghku Wang River to the south, the Chinese border to the west, and the Adung Wang to the east and north (Figure 1). Many of the sightings were from the foothills of Mt Hkakabo-Razi, where hunters reported seeing it mostly alone or in pairs, but sometimes in groups of up to 10 . One hunter reported a group of 30 in 1960 . Hunters claimed that it was a difficult animal to approach and that it could be killed only from a distance.

Takin Budorcas taxicolor: Found generally between 1500 and $4500 \mathrm{~m}$, this heavily hunted species was considered to be common still in the mountain forests of Hkhakabo-Razi Protected Area, where they were seen by local hunters in groups as small as 5-10, and as large as 50-60 individuals. Takin horns and skins were purchased by Chinese traders, and some hunters consumed takin flesh as a tonic. Takin, like red panda, were reported to migrate to lower elevations, close to villages, during the winter.

Red goral Naemorhedus baileyi: Although this species was first described from Tibet (Pocock, 1914), the skin of a similar animal was collected by Lord Cranbrook in the Adung Valley of North Myanmar in 1931 (Kingdon-Ward, 1932). The Burmese specimen was described nearly three decades later as a separate species, Naemorhedus cranbrooki (Hayman, 1961). Further investigation by Groves and Grubb (1985) showed that both animals were the same species.

With a reported distribution limited to North Myanmar and adjacent parts of Assam, western Yunnan and south-east Tibet (Corbet and Hill, 1992), this small goral is usually found in mountainous areas above $2500 \mathrm{~m}$. Although its distribution is often considered sympatric with that of the common goral $(N$. caudatus), our data indicate that the two

(c) $1998 \mathrm{FFI}$, Oryx, 32 (3), 201-208 species do not overlap in North Myanmar, an observation also reported by Hayman (1961) and Ma et al. (1994). Within the Hkakabo-Razi Protected Area, N. baileyi was the only goral reported present, whereas south of the Nam Tamai, where $N$. caudatus was reported, the red goral was absent.

In the Hkakabo-Razi Protected Area, the red goral was reported as common to abundant in the surrounding mountains. Along with the black muntjac, the red goral is heavily hunted for food and trade, with the meat consumed locally and the skins sold to traders. Many hunters claimed to depend on the meat of red goral and black muntjac for their long hunting journeys for musk deer. The village of Gawai claimed kills of up to 50 red gorals a year, while Tahawndam estimated an annual offtake of 20-30 red gorals. During our 1997 expedition, four red gorals were observed individually on steep rocky outcrops between Tahawndam and Rasang Camp. Despite the hunting pressure, the red goral was reported to be one of the most common large mammals north of the Nam Tamai River. Myanmar probably contains a significant portion of the world population of this geographically restricted species.

Serow Naemorhedus sumatraensis: Two subspecies of serow are known from Myanmar. They differ primarily in coat colour. Naemorhedus s. milne-edwardsi, the black serow, with head and body brownish-black and the legs below the knees rusty-red, and N. s. rubidus, the red serow, which is smaller, red in colour and with a shorter mane than that of the black subspecies (Tun Yin, 1967). Tun Yin (1967) reported the red serow only from the Arakan Hills in south-west Myanmar, while Milton and Estes (1963) described a 'red-brown color phase' of the serow from Chakuan Pass in northern Myanmar. During this expedition, two heads of the red serow were examined from the villages of Tashuhtu and Tazungdam in Hkakabo-Razi Protected Area, and two heads and a skin were obtained from the Putao market. In Shangong, north-west of Putao, hunters claimed that only red serow occurred in the forests. 
The black serow was considered to be relatively common by hunters questioned in nearly all villages visited during the 1997 survey. The exceptions were the villages of Pangnamdim and Guba, where hunters said they were now absent. This species is heavily hunted with snares, primarily for its skin and horns, which are valued by Chinese traders. Other parts of the animal that are used for traditional remedies include the legs, tongue and heart.

\section{Family Canidae}

Golden jackal Canis aureus: The most northern distribution of the Asiatic jackal is placed far to the south of North Myanmar (Lekagul and McNeely, 1988; Corbet and Hill, 1992). During our 1997 expedition, a vest made from the skin of a golden jackal was examined in Putao, with the animal reportedly killed in the forests east of the Mai Hka River. Although descriptions and photographs of this animal were often confused with the wild $\operatorname{dog}$ Cuon alpinus and the wolf Canis lupus, the golden jackal was known to some hunters. While this species appears to be present but not common in North Myanmar, its status and distribution remain uncertain.

Red $\operatorname{dog}$ Cuon alpinus: This species was known throughout the survey area, where it was considered to be moderately common as far as the northern village of Tashuhtu, beyond which it was considered to be rare. The skin and skeleton of a recent red dog kill was examined in Guardhtu, although most villages did not generally save or trade in the parts of this species. With a range that extends into upper montane forest areas (Lekagul and McNeely, 1988), these canids are probably the most significant large predators in the Sino-Himalayan region of Myanmar, where there is a paucity of other large predators.

Wolf Canis lupus: During the Vernay-Cutting Expedition to north-east Myanmar, Anthony (1941) described an encounter with a small wolf, which the local people called 'jungle dog'. In 1948, B. E. Smythies, in the same vicin- ity as Anthony, came 'face to face' with a wolf (pers. comm.). Milton and Estes (1963), while exploring the mountains west of Putao, near the Indian border, observed tracks that they believed might be those of a wolf.

During our survey there were occasional reports of wolf-like animals that were the size of small dogs, or reports of 'wolves' attacking livestock. However, using photographs and descriptions, hunters frequently confused wolves with red dogs and jackals. Only one report, from Pangnamdim, where a wolf-like animal was seen on 'a few occasions' on the icy mountains near the Chinese border to the east, seemed worthy of note.

The reports from earlier naturalists, and evidence of wolves reported from the adjoining Galigongshan region of China (Ma et al., 1994), indicate a possibility that wolves may occasionally occur in Myanmar. Although we found no conclusive evidence for the presence of wolves during our survey, further investigation is needed.

\section{Family Ailuridea}

Red panda Ailurus fulgens: Reported between 2200 and $4800 \mathrm{~m}$ (Corbet and Hill, 1992), this species was considered relatively common in the forests north of the Nam Tamai River. Hunters reported red pandas close to their villages when animals migrated down from the higher elevations during the winter. Although hunters did not actively seek this animal, they killed them when they encountered them, or when they captured them in snares set on the ground for musk deer. Red panda skins were purchased by Chinese traders.

\section{Family Mustelidae}

Back-striped weasel Mustela strigidorsa: Although this species was not listed from Myanmar by Tun Yin (1967), North Myanmar is one of the few spot localities indicated by Corbet and Hill (1992). Fewer than a dozen skins of this species are recorded in museum collections world-wide. During our expedition, a skin of $M$. strigidorsa was obtained in the village of Lanzatu, where it was said to 
be common. It was also reported to be common around Gawlei and Shinshanku and present, but not common, around Pangnamdin. After reaching Tashuhtu, the back-striped weasel was unknown to the villagers. This species was also recently found in the southern Gaoligongshan region of Yunnan Province, near the border of China and Myanmar (Ma et al., 1994).

Stone marten Martes foina: Known from rocky, open areas of south-west China and the Himalayas above $1500 \mathrm{~m}$ (Corbet and Hill, 1992), this species has never. been recorded from Myanmar. One skin of a stone marten was acquired from a hunter in Karaung village, who claimed to have killed the animal at his plantation, but said he had never seen such an animal before. Other hunters who were shown this skin were also unable to recognize this species. Not considered to be endangered elsewhere throughout its range, the pelt of this species is a valuable trade item in China (Grzimek, 1990). Further confirmation of this species's presence and distribution in North Myanmar is necessary.

\section{Family Felidae}

Tiger Panthera tigris: North Myanmar was recently designated a high-priority area for seeking information on tiger presence and relative abundance (Dinerstein et al., 1997). Interviews with hunters throughout Putao township in 1996 indicated that, while tigers had been present in the past, they had become either rare or extirpated over the last decade. Only one 10year-old tiger jaw was found in Putao, and an old hunter remembered selling tiger bones more than two decades ago. The most recent reports of tigers were from the mountainous western border with India, where they were also reported as rare. Milton and Estes (1963) reported only a few tiger tracks from the mountains west of Putao nearly four decades earlier, and the Vernay-Cutting Expedition of 1938-39 saw evidence of tigers in only two localities (Anthony, 1941).

During our 1997 expedition, tiger presence between the Mali Hka and the Mai Hka was re- ported as uncommon to non-existent. However, a single tiger was reported killed near Ratbaw in 1993. Within the Hkakabo-Razi Protected Area, no tigers were reported and no evidence of tigers was seen. Although the area east of the Mai Hka was not investigated, surveys in the Gaoligongshan region of China also reported that tigers were gone from areas where they had once been present ( $\mathrm{Ma}$ et al., 1994).

\section{Family Hylobatidae}

Hoolock gibbon Hylobates hoolock: This species was heard frequently and considered relatively abundant in the forests surrounding most village areas along the survey route north-east of Putao, until reaching the Nam Tamai River. Although not considered as a particularly valuable trade species, the skins were sold in Putao as shoulder bags, and the brain was considered good for headaches. The Nam Tamai appeared to be a dispersal barrier for these gibbons, and none was heard or reported within the Hkakabo-Razi Protected Area.

\section{Other species of interest}

Three large mammal species-elephant Elaphus maximus, gaur Bos gaurus and Sumatran rhinoceros Dicerorhinus sumatrensis which historically inhabited parts of North Myanmar, no longer survive north of Putao. Between the Mali Hka and the Mai Hka Rivers, elephants and Sumatran rhinos were reported to be present in some areas up until 1980, and a few Sumatran rhinos were still reported a decade ago.

There was a single report of snow leopard Uncia uncia from a hunter in the village of Pangnamdim, who claimed his brother had killed two of the animals a decade earlier in the mountains along the China border. No other hunters in the region recognized the snow leopard. Lynx Lynx lynx and red fox Vulpes vulpes, both reported from the Galigongshan Mountains in China (Ma et al., 1994), were not recognized by hunters during these surveys and no evidence of their presence was found in North Myanmar. 


\section{Acknowledgements}

The expedition was funded by the Wildlife Conservation Society and hosted by the Myanmar Forest Department. We thank the Ministry of Forestry, the Director-General of the Forestry Department and the Ministry of Defence for their assistance and interest in this expedition. We also thank U Saw Lwin of Myanmar Flora, and the University of Yangon for providing scientific expertise. Finally, we thank George Amato for genetic analysis and critical input, and Melissa Conner for maps.

\section{References}

Anthony, H.E. 1941. Mammals collected by the Vernay-Cutting Burma Expedition. Publications of the Field Museum of Zoology, Chicago, 27, 37-123.

Corbet, G.B. and Hill, J.E. 1992. The Mammals of the Indomalayan Region. Oxford University Press, New York.

Cowan, I.M. and Holloway, C.W. 1973. Threatened deer of the world: conservation status. Biological Conservation, 5 (4), 243-250.

Dinerstein, E., Wikramanayake, E., Robinson, J. et al. 1997. A Framework for Identifying High-Priority Areas and Actions for the Conservation of Tigers in the Wild. World Wildlife Fund/Wildlife Conservation Society, Washington.

Dollman, J.G. 1932. Mammals collected by Lord Cranbrook and F. Kingdon Ward in Upper Burma. Proceedings of the Linnaean Society of London, 145, 9-11.

Gao, Y.-T. 1985. Classification and distribution of musk deer (Moschus). In Contemporary Mammology in China and Japan (ed. T. Kawamichi), pp. 113-116. Mammalogical Society of Japan, Osaka.

Groves, C.P. and Grubb, P. 1985. Reclassification of the serows and gorals (Nemorhaedus: Bovidae). In The Biology and Management of Mountain Ungulates (ed. S. Lovari), pp. 45-50. Croom Helm, London.

Groves, C.P., Wang, Y. and Grubb, P. 1995. Taxonomy of musk deer, genus Moschus (Moschidae, Mammalia). Acta Theriologica Sinica, 15 (3), 181-197.

Grzimek, B. 1990. Encylopedia of Mammals, Vol. 3. McGraw-Hill Publishing Co, New York.

Hayman, R.W. 1961. The red goral of the north-east frontier region. Regional Proceedings of the Zoological Society of London, 136 (3), 317-324.

Kingdon-Ward, F. 1932. Explorations on the Burma-
Tibet frontier. Geographical Journal (London), 80, 465-483.

Kingdon-Ward, F. 1936. The Irrawaddy plateau. Geographical Journal (London), 94, 293-308.

Kingdon-Ward, F. 1944. A sketch of the botany and geography of North Burma. Journal of the Bombay Natural History Society, 44, 550-574.

Kinnear, N.B. 1934. On the birds of the Adung Valley, North-East Burma. Journal of the Bombay Natural History Society, 37, 347-368.

Lekagul, B. and McNeely, J. 1988. Mammals of Thailand. 2nd edn. Saha Karn Bhaet Co., Bangkok.

Lu, H.-G. and Sheng, H.-L. 1984. Status of the black muntjac Muntiacus crinifrons in eastern China. Mammal Review, 14 (1), 29-36.

Ma, S.-L., Han, L. and Lan, D. 1994. Bird and Mammal Resources and Nature Conservation in the Gaoligongshan Region, Yunnan Province, People's Republic of China. Conservation Biology Center, Kunming Institute of Zoology, Kunming.

Milton, O. and Estes, R. 1963. Burma Wildlife Survey 1959-60. Special Publication No. 15, American Committee for International Wildlife Protection, New York.

Ohtaishi, N. and Gao, Y. 1990. A review of the distribution of all species of deer (Tragulidae, Moschidae and Cervidae) in China. Mammal Review, 20 (2/3), 124-144.

Pocock, R.I. 1914. Description of a new species of goral. Journal of the Bombay Natural History Society, 23, 32-33.

Rabinowitz, A., Amato, G. and Saw Tun Khaing. 1998. Discovery of the black muntjac Muntiacus crinifrons, in north Myanmar. Mammalia, 62 (1).

Schaller, G. 1977. Mountain Monarchs: Wild Sheep and Goats of the Himalaya. University of Chicago Press, Chicago.

Tun Yin. 1967. Wild Animals of Burma. Rangoon Gazette Ltd, Rangoon.

Wang, Q. and Hu, X. 1985. Distribution and food of the black muntjac in Anhui Province. In Contemporary Mammology in China and Japan (ed. T. Kawamichi), pp. 121-124. Mammalogical Society of Japan, Osaka.

Alan Rabinowitz and Saw Kun Khaing, Wildlife Conservation Society, 185th Street and Southern Boulevard, Bronx, NY 10460, USA.

Received 10 November 1997

Accepted 3 March 1998 